\title{
COMPARATIVE STUDY OF MECHANICAL AND THERMAL CHARACTERIZATION OF GLASS/CARBON HYBRID COMPOSITE
}

\author{
Praveenkumar S Totiger ${ }^{1}$, Mahesh S Gothe ${ }^{2}$, Suneel K Nagavi ${ }^{3}$, R G Mulimani ${ }^{4}$ \\ ${ }^{1}$ Praveen S Totiger, Department of Mechanical Engineering, Rural Engineering College Hulkoti, Karnataka, India \\ ${ }^{2}$ Mahesh S Gothe, Department of Mechanical Engineering, Rural Engineering College Hulkoti, Karnataka, India \\ ${ }^{3}$ Suneel K Nagavi, Department of Mechanical Engineering, Rural Engineering College Hulkoti, Karnataka, India \\ ${ }^{4} R$ G Mulimani, Department of Mechanical Engineering, Rural Engineering College Hulkoti, Karnataka, India
}

\begin{abstract}
In this paper, the mechanical characterization of glass-carbon fiber reinforced hybrid polymer composite with epoxy resin as the matrix was investigated. Initially the basic mechanical characterization like tensile, bending, impact and wear tests have been carried out experimentally along and across the fiber orientation for the glass-carbon hybrid composite. The specimens were prepared and tested according to ASTM Standards. Glass Fiber Reinforced Polymer (GFRP) composites have been widely used high strength, low weight structural applications as compared to their metallic counterparts. Carbon Fiber Reinforced Polymer $(C F R P)$ composites posses superior specific strength and modulus but have a lower failure strain and high cost. Hence, the combination of both glass and carbon fiber in polymer composite may yield optimized mechanical properties.
\end{abstract}

Keywords: Hybrid composites, Mechanical characterization, Thermal characterization.

\section{INTRODUCTION}

\subsection{Introduction to Composite Materials}

Composite material is a material system composed of two or more macro constituents differing in form and material composition and that are essentially insoluble in each other.(6)

Elemental Level: At this level single molecules or crystal cells or all materials composed of different atoms would be regarded as composites

Ex: Compounds, Polymers, Ceramics

Micro structural Level: At this level a composite would be defined as a material composed of two or more crystals, molecular structures or phases

Ex: A multi phase alloy of carbon \& iron like steel

Macro structural Level: At this level with which I was principally concerned, I dealt with gross structural forms of the constituents

Ex: Matrices, particles and fibers

In the technologically advanced era that we currently live in, there is a growing demand for cheaper and more durable materials for a variety of applications. Previously metals and metal alloys were used to manufacture anything and everything from paperclips to skyscrapers. Then plastics were discovered and a revolution began where plastics started replacing metal components, for example, gears, bearings, etc. Plastics are easier to mould into complex parts as well as being lighter than their metal counterparts and just as durable. Initially plastics were expensive, but as there application and demand in everyday life increased, the manufacturing costs of plastic components decreased. The use of plastic components are limited to low end applications such as food containers and dustbins due to their relatively low strength. High-end applications such as automotive, marine and aerospace structures still required the use of metals and their alloys. Thus there was a need for a strong yet lightweight material and hence composite materials were developed and this field is now the attractive area of Research both for Engineers as well as academicians.

A composite material is formed by the combination of two or more materials that have different properties. These different materials work together to give the overall composite material enhanced properties that are better than those of the separate constituent parts. The argument now would be that a composite material is similar to an alloy. This, however, is not the case because in an alloy the different materials or constituents dissolve or blend into each other to form the final material. In the final alloy the different materials are indistinguishable. In a composite, on the other hand, the different materials do not dissolve or blend into each other and can be easily distinguished from one another [5]. A composite material is made up of two basic constituents, namely, a matrix and the reinforcement [5]. The reinforcement is usually the constituent that provides the composite with its strength. It can be either in particulate form or fibers. The matrix is the constituent that surrounds and binds the reinforcement as well as serves the protection against damage [5]. It also aids in the distribution of the applied load to the reinforcement. 


\subsection{Importance and Significance of the Proposed}

\section{Work}

In accordance with its name, a hybrid composite consists of more than one material, i.e. reinforced fiber and binding agent. The reinforcing material in present work is carbon and glass fiber. Other materials used are among other fiberlike aramid, silicon carbide, and boron etc.

Vinyl ester or polyester is also used as binding agent. Epoxy is used as binding agent in the present work.. Fiber gives firmness to the composite, the binding agent binds the fibers' tightly together, distributes the load in the fiber layers and gives an object the form needed. Hybrid composites contain more than one type of fiber in a single matrix material. In principle, several different fiber types may be incorporated into a hybrid, but it is more likely that a combination of only two types of fibers would be most beneficial [2]. They have been developed as a logical sequel to conventional composites containing one fiber. Hybrid composites have unique features that can be used to meet various design requirements in a more economical way than conventional composites. This is because expensive fibers like graphite and boron can be partially replaced by less expensive fibers such as glass and Kevlar [2].

\section{OBJECTIVES OF THE PRESENT WORK}

$>\quad$ To Fabricate the Hybrid composite Using carbon and glass as reinforcements and epoxy resin as the Matrix material

$>\quad$ To evaluate properties like Tensile strength, Flexural Strength, Impact strength, Abrasive Wear Resistance, Heat Deflection Temperature (HDT), Vicat Softening Temperature (VST) and Hardness in Mechanical Characterization.

\section{FABRICATION OF THE HYBRID}

\section{COMPOSITE MATERIAL}

\subsection{Fabrication Processes of Composites}

Following are the various techniques used for fabrication of Fiber Reinforced Composites

$>$ Hand Lay-Up Technique

$>$ Vacuum Bag Molding

$>$ Vacuum Assisted Resin Transfer Molding (VARTM)

$>$ Filament Winding

$>$ Pultrusion

\subsubsection{Hand Lay-Up Technique}

This process is suited for making large, high strength parts at low to medium volumes. A combination of reinforcements in roll form is laid into an open mold and impregnated with resin. When the resin cures, the surface of the mold is replicated on the side of the composite facing the mold. Resins are impregnated by hand, see Figure 2, into which fibers are in the form of woven, knitted, stitched or bonded fabrics. This is usually accomplished by rollers or brushes, with an increasing use of nip-roller type impregnators for forcing resin into the fabrics by means of rotating rollers and a bath of resin. Laminates are left to cure under standard atmospheric conditions.

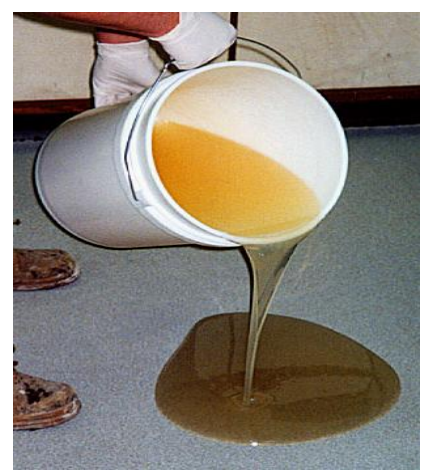

Fig 1 : Epoxy resin (LAPOX L12)

In the Present Work Epoxy Resin used is LAPOX L12 with Hardener K6 as the curing Agent.

\subsection{Mould Box Design}

The design of mould box involves $20 \mathrm{~mm} \mathrm{~L}$ section and it is cut into four pieces with a length of $365 \mathrm{~mm}$, it is welded to get the required size of mould box as shown in the figure below.

The hand lay-up process produces parts from an open, glass/carbon reinforced epoxy resin mould. The mould surface is treated with several layers of release wax.. Over the release wax a layer of epoxy resin of calculated weight is poured uniformly then glass fiber mat is laid.

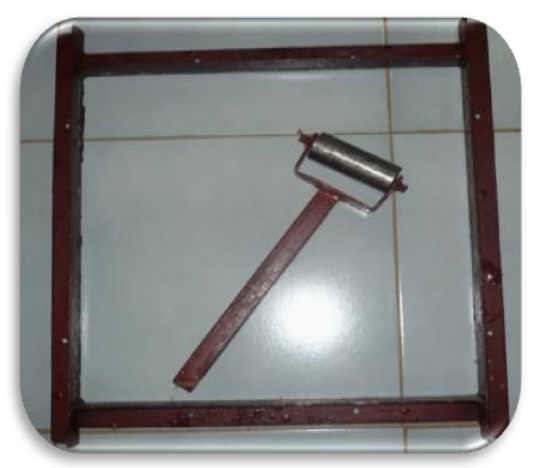

Fig 2 : Mould Box

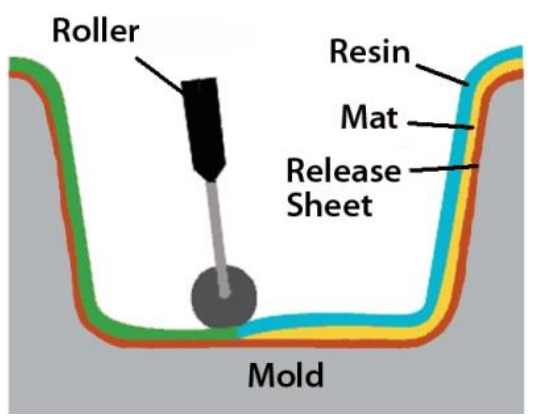

Fig 3: Hand Lay-Up Technique 
Each glass layer is pressed by hand with rollers to work the epoxy resin into the glass fiber. Then again one more layer of epoxy resin is poured uniformly and carbon fiber mat is laid and pressed. The combination of this 2 layer of epoxy, and one layers of glass and carbon will make a hybrid composite layer. Depending upon the required thickness three to nine hybrid composite layers are laid one above the other. This is allowed to cure or hardened depending on the desire strength of the part at the room temperature and once the epoxy is cured, the part is removed from the mould. The part requires trimming and post mould surface preparation.

Hand lay-up parts can consist of any size or configuration. Moreover, the process does not require any special tools.

Table 1 Some Important Characteristics of Epoxy

\begin{tabular}{|l|l|l|l|l|}
\hline $\begin{array}{l}\text { Density } \\
\mathrm{kg} / \mathrm{m}^{3}\end{array}$ & $\begin{array}{l}\text { Strengt } \\
\text { h Mpa }\end{array}$ & $\begin{array}{l}\text { Modulu } \\
\text { s E Mpa }\end{array}$ & $\begin{array}{l}\text { Poisson' } \\
\text { s ratio ,v }\end{array}$ & $\begin{array}{l}\text { Cure } \\
\text { shrinkage } \\
\%\end{array}$ \\
\hline $1.2-1.3$ & $50-125$ & $2.5-4$ & $0.2-0.33$ & $1-5$ \\
\hline
\end{tabular}

Table 2 Some Important Characteristics of Polyester

\begin{tabular}{|l|l|l|l|l|}
\hline $\begin{array}{l}\text { Density } \\
\mathrm{kg} / \mathrm{m}^{3}\end{array}$ & $\begin{array}{l}\text { Strengt } \\
\text { h Mpa }\end{array}$ & $\begin{array}{l}\text { Modulu } \\
\text { s E Mpa }\end{array}$ & $\begin{array}{l}\text { Poisson' } \\
\text { s ratio ,v }\end{array}$ & $\begin{array}{l}\text { Cure } \\
\text { shrinkage } \\
\%\end{array}$ \\
\hline $1.1-1.4$ & $30-100$ & $2-4$ & $0.2-0.33$ & $5-12$ \\
\hline
\end{tabular}

\subsection{Calculations for Preparing 4mm Thickness}

\section{Composite Sheets}

\section{Observations}

Mass of Resin

Volume of Resin Taken

Diameter of beaker

$\mathrm{m}=114 \mathrm{gms}$

$\mathrm{v}=(\Pi / 4) \mathrm{xd}^{2} \mathrm{xh}$

$\mathrm{d}=44 \mathrm{~mm}$

Height of Resin taken in Beaker $\quad \mathrm{h}=60 \mathrm{~mm}$

Volume

Density

$=1249.58 \mathrm{~kg} / \mathrm{m}^{3}$

$$
\mathrm{v}=9.123 \times 10^{-5} \mathrm{~m}^{3}
$$

In our Hybrid composite Volume $=304.8 \times 304.8 \times \mathrm{xt} \mathrm{mm}^{3}$ (as $1 \mathrm{ft}=304.8 \mathrm{~mm}$ )

As the fabrics are cut into sizes of $1 \times 1 \mathrm{ft}$, thickness to be evaluated as to number of layers required for particular thickness of the sheet during fabrication.

$0.3048 \times 0.3048 \times t=\left(114 \times 10^{-3}\right) /(1249.58)$

$\mathrm{t}=0.9819 \times 10^{-3} \mathrm{~m} \quad \square=1 \mathrm{~mm}$

Which is almost equals $1 \mathrm{~mm}$. Hence Resin to be poured for $1 \mathrm{~mm}$ thickness is Approximately $120 \mathrm{gms}$.

Thickness of carbon fabric $-0.2 \mathrm{~mm}$

Thickness of glass fabric $-0.3 \mathrm{~mm}$

For $4 \mathrm{~mm}$ thickness composite sheets we need,

Resin - 5 layers

Glass - 2 layers

Carbon - 2 layers

\section{EXPERIMENTAL TESTS}

FOR

\section{MECHANICAL CHARACTERIZATION}

All Tests are conducted as per ASTM standards as follows

Table 3 Experimental Tests in Mechanical Characterization

\begin{tabular}{|l|l|}
\hline Test & Standard \\
\hline Tensile & ASTM D638 \\
\hline Flexural (Bending) & ASTM D790 \\
\hline Impact & ASTM D256 \\
\hline Abrasive Wear Test & ASTM \\
& D1242 \\
\hline Heat Deflection Temperature & ASTM D \\
(HDT) Test & 648 \\
\hline Vicat Softening Temperature Test & ASTM \\
(VST) & D1525 \\
\hline
\end{tabular}

The present study involves the evaluation of mechanical properties of Carbon and glass which are used for fabrication of a hybrid composite using epoxy resin as the matrix material. Carbon and glass are used as fiber reinforcements and composites are fabricated with each set containing composite plates of varying thickness by varying the number of layers during fabrication.

The following methods are being adopted for various activities:

1) Fabrication by Hand Lay Up Technique.

2) Mechanical Characterization includes the tests done on the Material after Fabrication as in Table 3

\subsection{Tensile Test}

\subsubsection{Specimen Preparation}

Glass /Carbon fiber reinforced epoxy material was taken in the form of $4 \mathrm{~mm}$ thick sheets. To test its orthotropic material properties the specimens are prepared in two different directions along and across the fiber direction as shown in figure 4

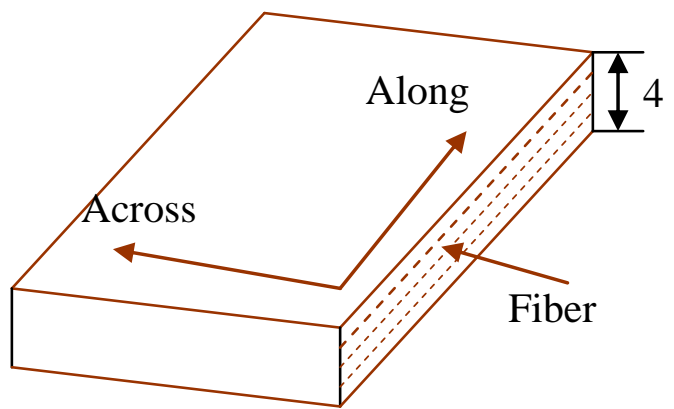

Fig 4 Prepared Specimen with Fiber directions

For tensile test total 12 specimens are prepared 6 alongspecimens and 6 across-specimens. Machining of the specimen was performed with Band saw cutting. After machining it was slightly polished with file so that all burrs are removed on the specimen. 
Aim: To Determine Tensile properties such as Tensile Strength and Young's Modulus

Significance and use: This test method is designed to produce tensile property data for control and specification of composite materials. These data are useful for qualitative characterization, engineering design and R\&D purposes.

Specimen size: The test specimen dimensions for reinforced composites, including high modulus orthographic laminates shall conform to the dimensions of Type 1.

The specimen dimension taken is $165 * 12 * 4$. (Where 12 refers to width of narrow section) as shown

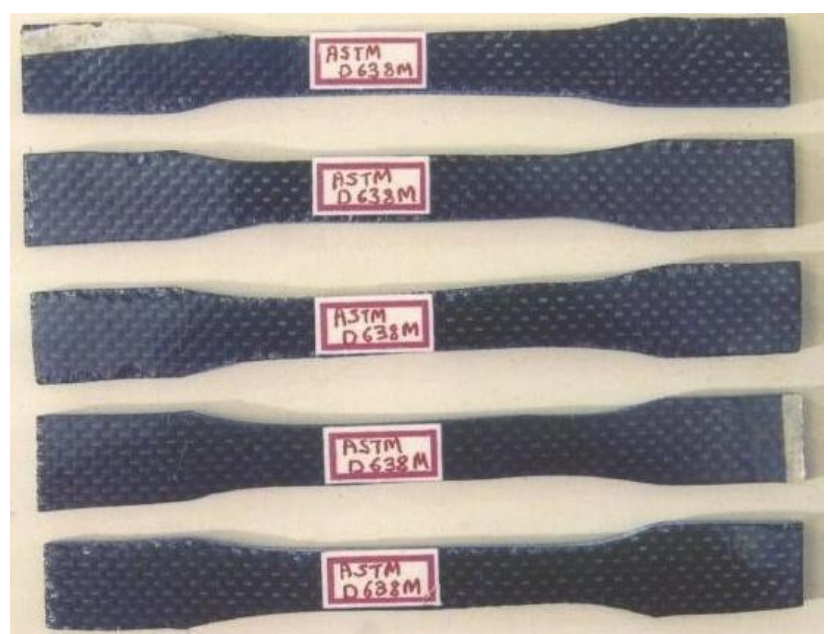

Fig 5 Prepared Tensile Test Specimens

For Tensile test total 12 specimens are prepared 6 Along and 6 Across-specimens. Machining of the specimen was performed with Band saw cutting. After machining it was slightly polished with file so that all burrs are removed on the specimen.

\section{Apparatus:}

1.Tensile testing machine or UTM, of constant rate of grip separation type comprising of fixed member, movable member, grips, drive mechanisms, load and extension indicators.

2. Plotter and micrometer.

Tensile test is a measurement of the ability of the material to with stand forces that tend to pull it apart and to determine to what extent the material before breaking The study of stress in relation to strain depicts the tensile property of the material

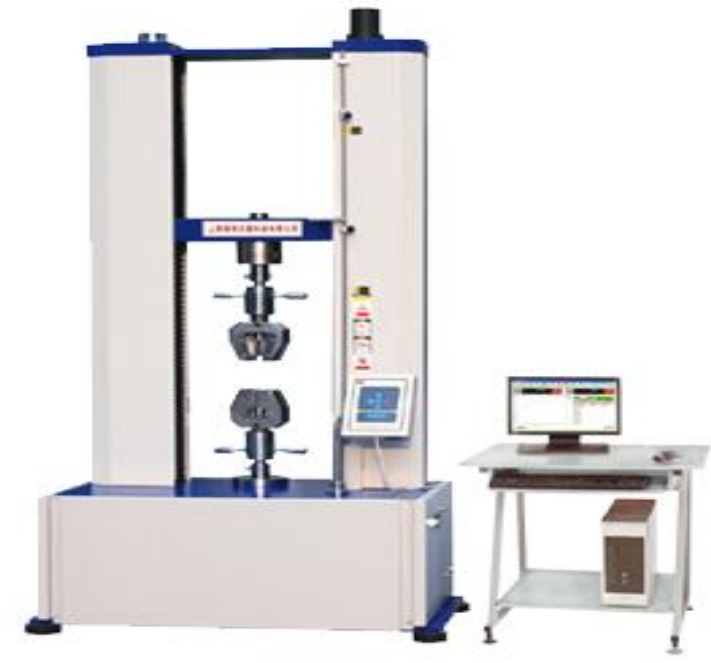

Fig 6 Computerized UTM.

Scope: This test method is the metric counterpart of the test method D638. Thus covers the tensile properties of plastics of any thickness upto $10 \mathrm{~mm}$. However for films of less then $1 \mathrm{~mm}$ thickness test method D882 is preferred

\section{Results of the Tensile Test}

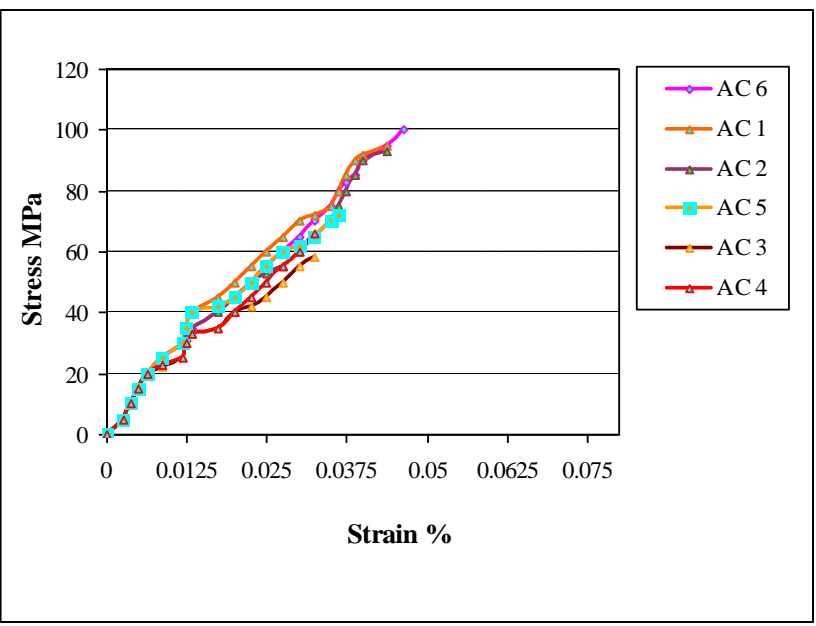

Fig 7 Stress vs Strain Curve for Across Tensile Specimens

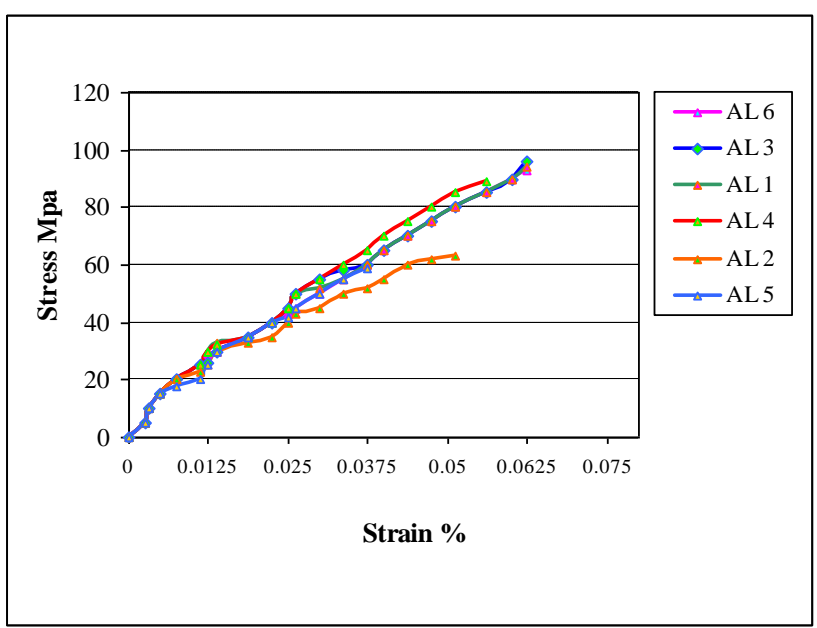

Fig 8 Stress vs Strain Curve for Along Tensile Specimens 
Table 4 Young's modulus for Along and Across specimens

\begin{tabular}{|l|l|l|}
\hline Specimen & $\begin{array}{l}\text { Young's Modulus } \\
\text { for Along specimen } \\
\text { N/mm }\end{array}$ & $\begin{array}{l}\text { Young's Modulus } \\
\text { for } \\
\text { Across specimen } \\
\text { N/mm }\end{array}$ \\
\hline 1 & 3404 & 3102 \\
\hline 2 & 2432 & 3167 \\
\hline 3 & 1495 & 2402 \\
\hline 4 & 3402 & 2318 \\
\hline 5 & 1756 & 2410 \\
\hline 6 & 1606 & 3198 \\
\hline Average & 2349.167 & 2766.167 \\
\hline
\end{tabular}

From the results it is clear that the difference in Young's modulus of along and across specimens is $417 \mathrm{MPa}$.

\subsection{Flexural Test (3-point Bending)}

Aim: To determine the flexural strength and flexural modulus using three point bending test.

Significance and use: This test generates the characteristics of a material in bending, which is useful in designing of structural parts used in the form of beam and if service failure occurs in bending then a flexural test is more relevant for design and specification then a tensile test.

\section{Apparatus:}

Flexural testing machine or UTM of constant rate of grip separation type comprising of fixed member, movable member, grips, drive mechanisms, 3-point bend fixture, load and extension indicators.

Flexural Strength is the ability of the material to withstand bending forces applied perpendicular to its longitudinal axis. The stresses induced due to flexural load are a combination of compressive and tensile stresses. Flexural properties are reported and calculated in terms of the maximum stress and strain that occurs at the out side surface of the test bar. Many do not break under flexure even after a large deflection that makes determination of the ultimate flexural strength impractical for many polymers. In such cases flexural yield strength is reported when the maximum strain in the outer fiber of the specimen has reached five percent.

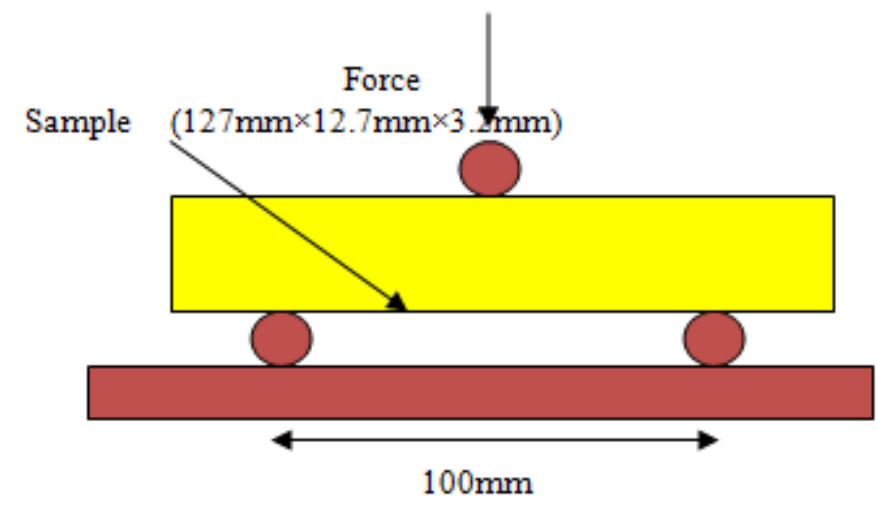

Fig 9 Schematic Representation of 3-point Bending Fixture

\section{Formula used}

$$
\text { Flexural Strength }=(3 \mathrm{Pl}) /\left(2 \mathrm{bd}^{2}\right) . \mathrm{N} / \mathrm{mm}^{2}
$$

Where,

$\mathrm{P}=$ Breaking load, $\mathrm{N}$

l=Span length, $\mathrm{mm}$

$\mathrm{d}=$ Depth, $\mathrm{mm}$

$\mathrm{b}=$ Width, $\mathrm{m}$

Flexural Modulus $=\left(1^{3} \mathrm{y}\right) /\left(4 b d^{3}\right) \mathrm{N} / \mathrm{mm}^{2}$

Where,

$y=$ slope of the tangent of the initial straight line portion of the load deformation curve.

$=\mathrm{dy} / \mathrm{dx}$

\section{Results of the Flexural Test}

Table 5 Results of the Flexural Test

\begin{tabular}{|l|l|l|}
\hline Specimen & $\begin{array}{l}\text { Flexural } \\
\text { Strength } \\
\text { N/mm }\end{array}$ & $\begin{array}{l}\text { Flexural Modulus } \\
\text { N/mm }\end{array}$ \\
\hline 1 & 510.18 & 955.36 \\
\hline 2 & 632.25 & 1006.36 \\
\hline 3 & 728.05 & 1084.53 \\
\hline 4 & 908.92 & 2053.89 \\
\hline 5 & 782.65 & 1212.66 \\
\hline 6 & 883.11 & 2256.9 \\
\hline Average & 740.86 & 1428.25 \\
\hline
\end{tabular}

\subsection{Impact Test}

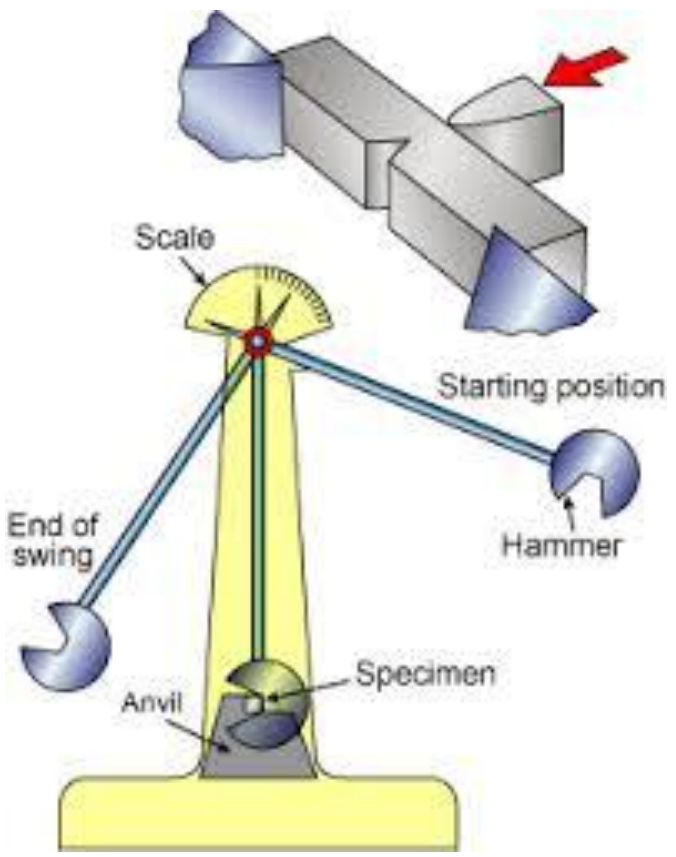

Fig 10 Impact Tester

Aim: To test the plastics for determination of loss of energy of the pendulum to break the Specimen which is an indication of the Impact strength of the material 
The Impact strength of the material are directly related to the overall toughness of the material. Toughness is the ability of the material to absorb applied Energy. The higher the impact strength of the material higher is the toughness of the material and vice versa. Impact resistance is the ability of the material to resist breaking under shock loading or the ability of the material to resist fracture under stress applied at high speed.

\section{Observations:}

Free Energy $=0.03 \mathrm{~J}$

1) Energy Delivered to the Specimen = Energy of the Impact - Free Energy

For Specimen 1

Energy Delivered $=0.2-0.03$

$=0.17 \mathrm{~J}$

2) Impact Strength = Energy Delivered to the Specimen J/ Width of the Specimen $m$

$=(0.17) /\left(5.09 \times 10^{-3}\right)$

$=33.39 \mathrm{~J} / \mathrm{m}$

Table 6 Results of Impact Test

\begin{tabular}{|c|c|c|c|}
\hline Specimen & $\begin{array}{l}\text { Width of the } \\
\text { Specimen m }\end{array}$ & $\begin{array}{l}\text { Energy } \\
\text { of the } \\
\text { Impact } \mathrm{J}\end{array}$ & $\begin{array}{l}\text { Impact } \\
\text { Strength } \\
\mathrm{J} / \mathrm{m}\end{array}$ \\
\hline 1 & $5.09 \times 10^{-3}$ & 0.20 & 33.39 \\
\hline 2 & $5.30 \times 10^{-3}$ & 0.19 & 30.18 \\
\hline 3 & $4.78 \times 10^{-3}$ & 0.19 & 33.47 \\
\hline 4 & $4.99 \times 10^{-3}$ & 0.21 & 36.07 \\
\hline 5 & $4.60 \times 10^{-3}$ & 0.22 & 41.30 \\
\hline 6 & $4.84 \times 10^{-3}$ & 0.19 & 33.05 \\
\hline \multicolumn{3}{|c|}{ Average Impact Strength } & 34.57 \\
\hline
\end{tabular}

\subsection{Abrasion Resistance of Plastics}

Aim: To Determine the Abrasive resistance of plastic materials, measured in terms of volume loss in accordance with ASTM D 1242

Significance and Use: The Abrasive resistance is affected by many factors such as the physical properties of the polymeric material particularly hardness, resilience and the type and the degree of the added filler. It is also affected by the conditions of the test such as the nature of the abradant, action of the abradant over the area of the specimen abraded and development and dissipation of heat during the test cycle.

Abrasion resistance is the resistance against abrasion. Abrasive resistance for plastic materials is measured using Table tester. In this test a specimen is clamped on to a turn table that rotates at specified revolutions per minute and the abrasive wheels press against the surface of the test piece. Centre of rotation of the test piece is offset from the line contact of the wheels and so the former is rotated. This causes the wheel to rotate and to cause an annular track into the specimen surface. Abrasive resistance is typically then measured by weight loss after given number of cycles.
In ASTM D 1242 two methods are standardized one has abrasive grit falling on to a rotating surface which is passed under a rotating weighted tool to which the test piece is mounted, pressing the grit against the plastic surface. In second the rotating bonded abrasive belt is pressed against the specimen surface as it is drawn uniformly across the belt surface. Both test methods measures the volume loss of test pieces from the recorded weight change and previously measured density. In the Present work first method is used in the Test Apparatus.

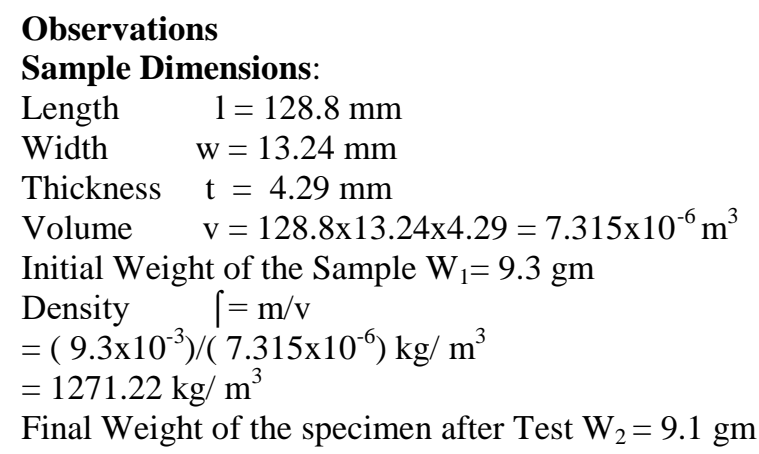

Table 7 Results of Abrasive Wear Test

\begin{tabular}{|c|c|c|c|c|c|}
\hline Material & $\begin{array}{l}\text { Densit } \\
\mathrm{y} \text { of } \\
\text { the } \\
\text { Sampl } \\
\text { e kg/ } \\
\mathrm{m}^{3}\end{array}$ & $\begin{array}{l}\text { Initial } \\
\text { Weig } \\
\text { ht gm }\end{array}$ & $\begin{array}{l}\text { Final } \\
\text { Weig } \\
\mathrm{ht} \\
\mathrm{gm}\end{array}$ & $\begin{array}{l}\text { Weight } \\
\text { Loss for } \\
1000 \\
\text { Revolutio } \\
\text { ns gm }\end{array}$ & $\begin{array}{l}\text { Volume } \\
\text { Loss for } \\
1000 \\
\text { Revolutio } \\
\text { ns cc }\end{array}$ \\
\hline $\begin{array}{l}\text { Carbon } \\
\text { Glass } \\
\text { Hybrid } \\
\text { Compos } \\
\text { ite }\end{array}$ & $\begin{array}{l}1271 \\
22\end{array}$ & 9.3 & 9.1 & 0.2 & 0.1573 \\
\hline
\end{tabular}

Volume Loss $=\left(\mathrm{W}_{1}-\mathrm{W}_{2}\right) / \uparrow$

$=(9.3-9.1) / 1271.22$

$=0.0001573 \mathrm{~m}^{3}$

Result: The Abrasion loss (Volume loss for 1000 revolutions) is $0.1573 \mathrm{~cm}^{3}$ of Hybrid Composite Sample

\subsection{Heat Deflection Temperature (HDT)}

Aim: To determine the temperature at which the arbitrary deformation occurs. When plastics are subjected to an arbitrary set of testing condition in accordance with ASTM D648

Heat Deflection temperature is defined as the temperature at which a standard test bar $(5 \times 1 / 2 \times 1 / 2)$ inch deflects 0.01 inch under a stated load of either $0.455 \mathrm{Mpa}$ or $1.820 \mathrm{Mpa}$. The Heat deflection temperature test is also referred to as Heat distortion temperature test and is commonly used for quality control and for screening and ranking materials for short term heat resistance.

Heat Deflection temperature is a single point measurement and does not indicate long term Heat resistance of plastic materials. The Specimen is immersed in a Heat transfer 
medium with a means of raising the temperature at $2^{+}-0.2$ ${ }^{\circ} \mathrm{C} / \mathrm{min}$. The temperature is reordered when the test bar deflected by $0.25 \mathrm{~mm}$ which is the HDT of the Specimen

\section{Appartus:}

The Equipment essentially consists of the following

Immersion Bath: The Heat transfer liquid with stirrer with heaters and controller to permit manual or automatic control of the temperature raise at the uniform rate of $2+-0.2{ }^{\circ} \mathrm{C} / \mathrm{min}$

Heat transfer liquid: Liquids such as silicone oil, mineral oil shall be used as heat transfer media. The liquid chosen should not effect the material being tested.

Specimen Support: A Suitable stand or the support for the specimen to be placed in the bath.

Deflection Measuring Device: A dial guage or any other device capable of measuring differences of $0.01 \mathrm{~mm}$ or better may be used.

Weights: A set of weights of suitable sizes so that the specimen can be loaded to a maximum fiber stress of 1.820 or $0.455+-2.5 \% \mathrm{Mpa}$. The weight of the rod and force excerted by spring or dial gage is determined and included as part of total load.

Thermometer: A thermometer or thermocouple adequate to cover the range being tested used

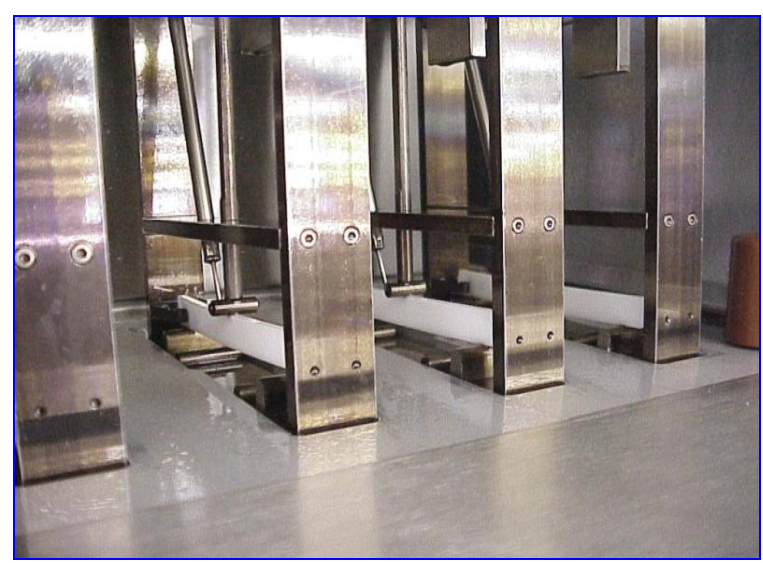

Fig 11 Heat Deflection Temperature Test Apparatus

\section{Test Procedure:}

The bars are placed under the deflection measuring device. A load of $0.45 \mathrm{MPa}$ or $1.80 \mathrm{MPa}$ is placed on each specimen. The specimens are then lowered into a silicone oil bath where the temperature is raised at $2^{\circ} \mathrm{C}$ per minute until they deflect $0.25 \mathrm{~mm}$

\section{Calculations}

The load is calculated using Equation

$$
\mathrm{P}=2 \mathrm{Sbd}^{2} / 3 \mathrm{~L}
$$

Where P - Load N

$\mathrm{S}$ - Maximum Fiber Stress in the specimen, N/mm 2

$\mathrm{b}$ - Width of the specimen $\mathrm{mm}$.

$\mathrm{d}$ - Depth of the specimen mm

L - Depth of the span between the supports, mm

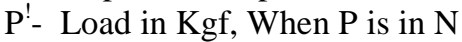

Load Calculation for Specimen 1

Length - $129 \mathrm{~mm}$

Depth - $13.35 \mathrm{~mm}$

Width - $4.86 \mathrm{~mm}$

$\mathrm{P}=\left(2 \times 1820 \times 1000 \times 4.86 \times 10^{-3} \times\left(13.39 \times 10^{-3}\right)^{2}\right) /\left(3 \times 129 \times 10^{-3}\right)$

$=8.146 \mathrm{~N}$

$\mathrm{P}^{!}=8.146 / 9.80665$

$=0.8307 \mathrm{Kgf}$

Applied Load $=0.8307 \times 1000$

$=830.7 \mathrm{gms}$

No need to Apply further loads as its within $1000 \mathrm{gm}$, if it exceeds 1000 again to add loads as the disc itself weighs 1000 gms which is mounted over the specimen.

Room Temperature $=30{ }^{\circ} \mathrm{C}$

HDT of the Specimen $1=42{ }^{\circ} \mathrm{C}$

HDT of the Specimen $2=46^{\circ} \mathrm{C}$

Average HDT of the Specimen $=(42+46) / 2=44^{\circ} \mathrm{C}$

Result: The HDT Temperature of the Material is $44^{\circ} \mathrm{C}$

\subsection{Vicat Softening Temperature}

Aim: To Determine the Vicat softening temperature of thermoplastic materials in accordance with ASTM D1525

Principle: Vicat softening point is the temperature at which a flat ended needle of 1 square mm circular cross section will penetrate a thermoplastic specimen to a depth of $1 \mathrm{~mm}$ under specified load and uniform rate of temperature rise

Rate A: 50 +or $-5^{\circ} \mathrm{C}$ /hour

Rate B: 120 +or $-12{ }^{\circ} \mathrm{C} /$ hour

Significance and Use: Data obtained by this test method may used to compare the Heat softening qualities of the thermoplastic materials. This test is useful in the areas of Quality control, development and Characterization of materials.

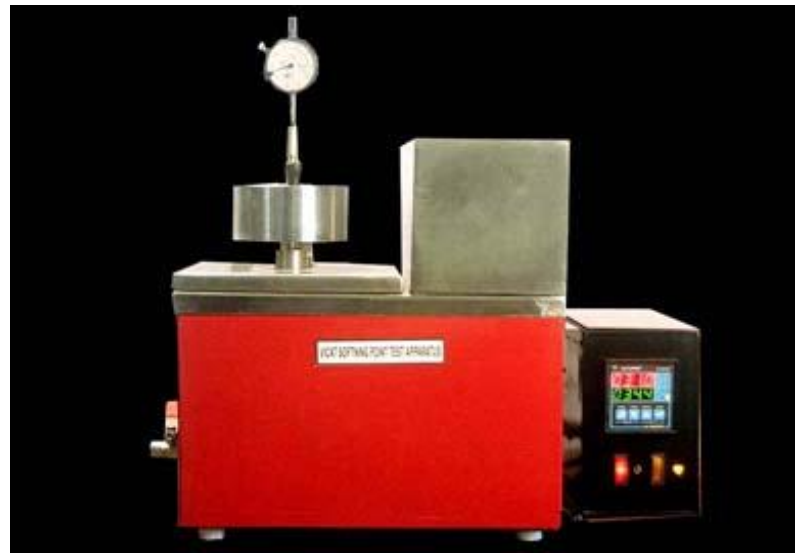

Fig 12 Vicat Softening Temperature Test Apparatus 
Apparatus: The equipment essentially consists of the following:

Immersion Bath: For heat transfer liquid with stirrer and heaters with controller to permit manual or automatic control of the selected bath temperature rise

Heat transfer liquid: Liquids such as silicone oils, glycerine, ethylene glycol and mineral oil shall be used as heat transfer media. The liquid chosen should not affect the material being tested.

Specimen Support: A Suitable stand or the support for the specimen to be placed in the bath.

Needle: Flat ended circular cross section of $1+0.05$ or $0.002 \mathrm{~mm}^{2}$ with flat tip and a length of 5 to $12.5 \mathrm{~mm}$ is used.

Weights: A set of weights on the needle point so that there is net load on it when apparatus is assembled.

Temperature Measurement Device: A thermometer or thermocouple adequate to cover the range being tested used

Penetration Measuring Device: A dial guage or any other device capable of measuring differences of $0.01 \mathrm{~mm}$ or better may be used.

Test Specimen: Use at least two specimens to test each sample. Flat specimen with minimum thickness of $3 \mathrm{~mm}$ and atleast $12 \mathrm{~mm}$ square is used.

\section{Observations}

Room Temperature $-30{ }^{\circ} \mathrm{C}$

Vicat Softening Temperature for Specimen $1 \mathrm{VST}_{1}=112{ }^{\circ} \mathrm{C}$

Vicat Softening Temperature for Specimen $2 \mathrm{VST}_{2}=116^{\circ} \mathrm{C}$

Average Vicat Softening Temperature $=114^{\circ}$

Table 8 Results of Vicat Softening Temperature Test

\begin{tabular}{|l|l|l|l|l|}
\hline Material & $\begin{array}{l}\text { Thickness } \\
\mathrm{mm}\end{array}$ & $\begin{array}{l}\text { Width } \\
\mathrm{mm}\end{array}$ & $\begin{array}{l}\text { Rate of } \\
\text { Temperature } \\
\text { Raise } \\
{ }^{\circ} \mathrm{C} / \mathrm{min}\end{array}$ & $\begin{array}{l}\text { VST } \\
{ }^{\circ} \mathrm{C}\end{array}$ \\
\hline $\begin{array}{l}\text { Hybrid } \\
\begin{array}{l}\text { Composite } \\
\text { carbon/glass }\end{array}\end{array}$ & 3.94 & 13.39 & 2 & 114 \\
\hline
\end{tabular}

Result: The Vicat Softening Temperature of the Material is $114^{\circ} \mathrm{C}$

\section{CONCLUSION}

The Incorporation of the carbon fiber improved the toughness by $10 \%$ as evident from the 3 point bending test. The weight loss for the tested specimen is found to be 0.2 $\mathrm{gm}$ and the Volume loss is found to be $0.1573 \mathrm{~cm}^{3}$ for the glass - carbon - epoxy hybrid polymer composite. These results are compared with the glass - aramid -epoxy hybrid polymer composites and the values shown in the above Table 7 is increased by $9 \%$. The elastic modulus is more dominant in along the fiber orientation also it is clear that the difference in average Young's modulus of along and across specimens is $417 \mathrm{MPa}$.

The heat distortion temperature of the glass - carbon epoxy polymer composites is found to be $44^{\circ} \mathrm{C}$ and the earlier results shows that for the glass - aramid -epoxy hybrid polymer composites was $58^{\circ} \mathrm{C}$. This shows that the aramid fiber is found to be more heat resistance rather than carbon fiber[1]. The Vicat Softening Temperature of the glass - carbon - epoxy polymer composites is found to be $114^{\circ} \mathrm{C}$ and the earlier results shows that for the glass aramid -epoxy hybrid polymer composites was $134^{\circ} \mathrm{C}$. This shows that the aramid fiber is found to be less softening quality due to temperature rather than carbon fiber.[1]

\section{REFERENCES}

[1] P.S.Shivakumargouda and $\mathrm{Dr}$ Dayanand Javali "Experimental Investigations on Mode I and Fracture Behaviour of Glass aramid fiber filled Epoxy polymer Composite" International Journal of Emerging technologies in Engineering Science \& Technology 3 (2) 2010

[2] Chamis, C. C., Lark, R. F.,'Hybrid composites State-of-the-art review: Analysis, Design, Application and Fabrication", NASA Technical Memorandum, NASA, TM X-73545

[3] Chou, Tsu-Wei, Kelly, Anthony, "Mechanical properties of composites." Annu. Rev.Mater. Sci. 1980. 10:229-59

[4] ISO 527-2 "Plastics- Determination of Tensile Properties"

[5] Fu S.-Y., Xu G., Mai Y.-W., "On the elastic modulus of hybrid particle/short-fiber polymer composites", Compos. Part B- Eng., 33, 291- 299, 2002.4.

[6] "Composite Materials" by Krishnan K Chawla Professor \& Chairman Department of Materials and Mechanical Engineering, The University of Alabama at Birmingham,USA

[7] “Composite Materials" by Autar K Kaw. 